\title{
Study on the Micro-structure and Micro-hardness of Thick Plate 16Mn Steel welding joints
}

Yong-Tao ZHAO ${ }^{1,2, a^{*}}$, Zi-Xiao LIANG ${ }^{2, b}$, Jun-Hui DONG ${ }^{1, c}$, Li-Ping ZHAO ${ }^{2, d}$

${ }^{1}$ School of Materials Science and Engineering, Inner Mongolia University of Technology, Hohhot, China; 010051

${ }^{2}$ School of Material and Metallurgy, Inner Mongolia University of Science and Technology, Baotou, China 014010

azyt0011@126.com, bShawnlzx@foxmail.com, cjhdong1009@163, dzhaoliping5195@126.com

${ }^{*}$ Corresponding author

Keywords: $16 \mathrm{Mn}$, Welding Joints, Micro-structure of Welding Joints, Micro-hardness.

\begin{abstract}
The 16Mn steel has good mechanical properties and welding performance, so it is used widely in pressure vessels, petroleum storage tanks and pipelines of oil and gas. Submerged arc welding was employed to weld $16 \mathrm{Mn}$, by OM, the microstructure in every region of welding joint was observed, by means of IT software, grain sizes of every region of welding joints were investigated. Then the micro-hardness of welding joints was measured through micro-hardness testing. The results show that $60 \mathrm{~mm}$ thick $16 \mathrm{Mn}$ steel plates, by submerged arc welding(in DC) and under appropriate craft conditions, the welded joint appearance is good, microstructure is uniform, it is ferrite+pearlite, the micro-hardness obtains the max at the edge of welded joint and HAZ. In HAZ zones, grain size grows up.

Thick welded steel plates of big line energy, high energy, low cooling rate and coarse grain of the welding heat affected zone (HAZ) may lead to welding joint ductility decrease, it is the weak link ${ }^{[1]}$ of the structural failure. Through research and analysis of $60 \mathrm{~mm}$ thick plate $16 \mathrm{Mn}$ steel welding joint microstructure and mechanical properties, it is possible to provide the theory foundation for the actual welding process of $16 \mathrm{Mn}$ thick plate.
\end{abstract}

\section{Experimental Materials and Methods}

This experiment used $16 \mathrm{Mn}$ steel plate as the base metal, the size was $1000 \mathrm{~mm} \times 400 \mathrm{~mm} \times 60 \mathrm{~mm}$ (length $\times$ width $\times$ thickness). The welding wire was H10Mn2, weld flux was sintered flux HJ107.

\section{Welding Process}

There were no defects on surface of the welded joint such as crack, undercut or shrinkage from the macroscopic observation. The surface was flat and smooth. Two pieces of thick plate 16Mn steel were chosen in this experiment, the form of the welding joint was depicted as Fig.1, multi-layer and multi-pass welding was carried out.
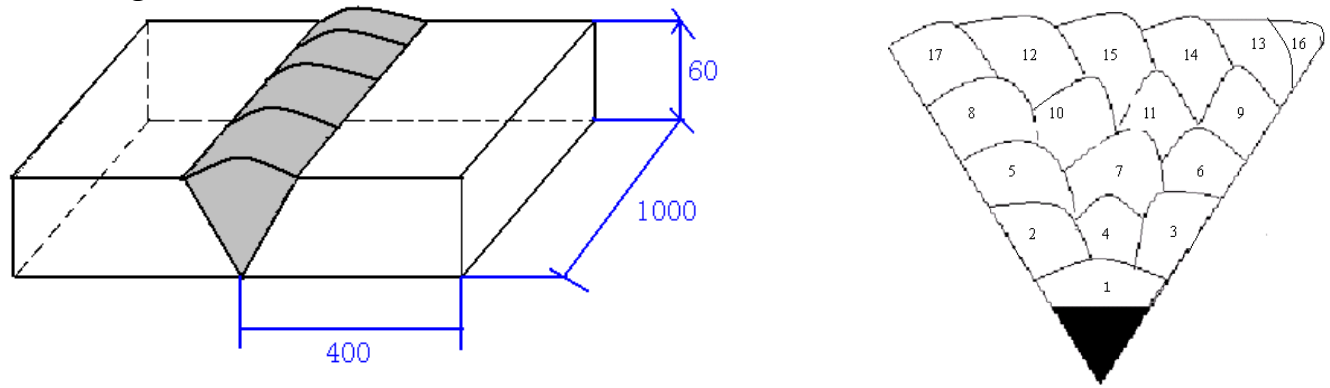

Fig. 1 The Form of 16Mn Steel Welding Joints 
16Mn steel Thick plates are suitable for various welding methods like shielded metal arc welding, submerged arc welding, electric slag welding[1] etc. The experiment with submerged arc welding method (use Lincolm 1000A in DC, 11NCOLM cantilevered automatic submerged-arc welding machine)was in DC. The welding craft was depicted as Tab.1.

Tab.1 The Welding Craft Parameters of 16Mn Steel

\begin{tabular}{cccccc}
\hline $\begin{array}{c}\text { Welding } \\
\text { method }\end{array}$ & $\begin{array}{c}\text { Current } \\
A)\end{array}$ & $\begin{array}{c}\text { Voltage } \\
(\mathrm{V})\end{array}$ & $\begin{array}{c}\text { Welding } \\
\text { speed }(\mathrm{mm} / \mathrm{m} \\
\text { in })\end{array}$ & $\begin{array}{c}\text { Diameter of } \\
\text { Welding Wire } \\
(\mathrm{mm})\end{array}$ & $\begin{array}{c}\text { Gap size } \\
(\mathrm{mm})\end{array}$ \\
\hline $\begin{array}{c}\text { Submerged } \\
\text { arc welding }\end{array}$ & $\begin{array}{c}450 \sim \\
500\end{array}$ & $28 \sim 31$ & $300 \sim 450$ & 4 & 60 \\
\hline
\end{tabular}

\section{Experimental Results and Analysis}

\section{Micro-structure observation and Analysis of 16Mn Steel Welding Joints}

Observation and Analysis of Matrix Micro-structure. From the Fig.2, the micro- structure of the thick plate $16 \mathrm{Mn}$ steel is ferrite+pearlite by hot rolling and air cooling. The micro-structure contains banded structure. $16 \mathrm{Mn}$ belongs to low carbon steel, through plastic deformation, lamellar structure[2] including ferrite and pearlite is presented parallel to the steel processing direction.

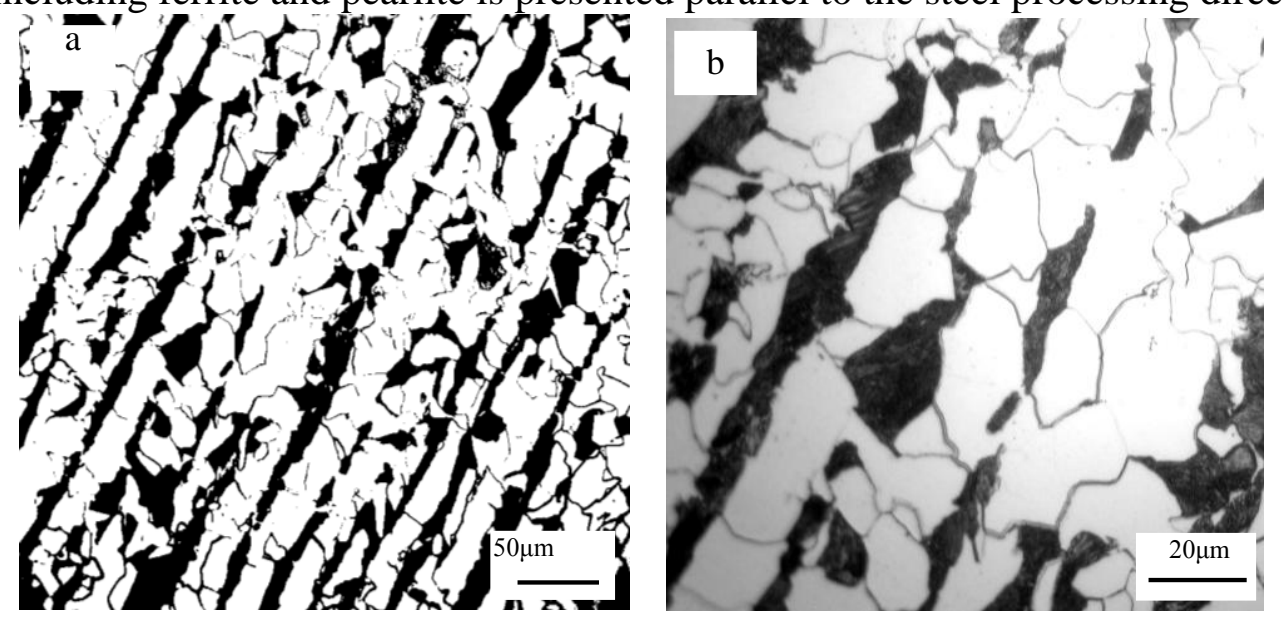

Fig. 2 The Micro-structure of 16Mn Steel Matrix

Observation and analysis of welding joint micro-structure. The micro-structure picture of the weld seam, fusion zone, HAZ and the matrix are depicted as Fig.3(a)-(d). From the picture, it is shown that micro-structure in every region of welding joints is ferrite+pearlite. Different position near to welded seam, different numbers micro-structure comes from different cooling rates.16Mn belongs to hypo-eutectoid steel, equilibrium micro-structure including ferrite and pearlite are obtained under air cooling condition. The faster cooling speed is, the less ferrite, the more pearlite. So the pearlite in Fig.2 (b) is more than (a). HAZ is extremely non-uniform region especially the area in the vicinity of the weld fusion line. Heating temperature is very high, cooling speed is fast, proeutectoid ferrite grows through intracrystalline and precipitates like an acicular shape along the certain crystal plane of austenite. By OM, acicular ferrite + pearlite can be observed as (c). This micro-structure is widmanstatten structure. The more the weld energy input is, the longer time it stays at high temperature, the coarser of grain size is. Moreover, it is easier to get the coarse widmanstatten structure [3]. In HAZ zone, the size of grain is greater than base metal because of heat effect [4]. It is depicted in Fig.3(d). 


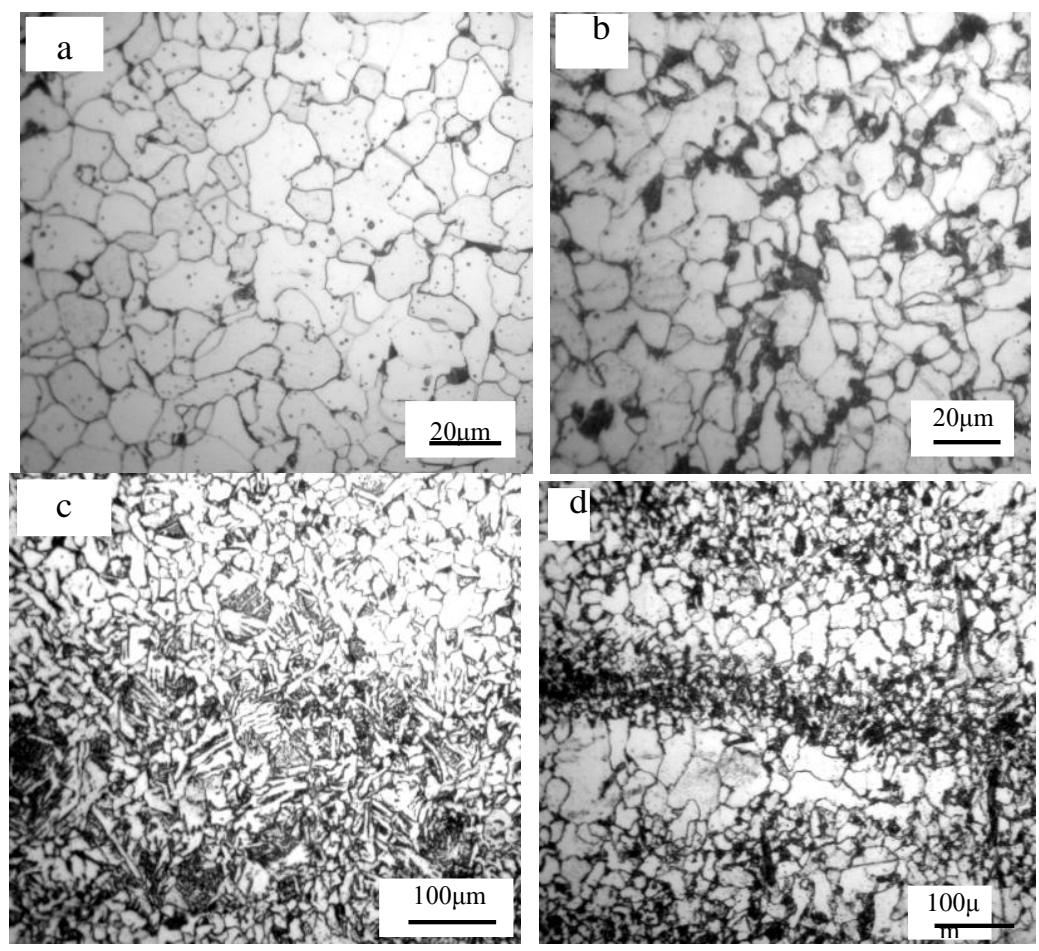

(a)The weld seam (b)The transition zone of the weld and fusion zone

(c)The Fusion zone (d)The transition zone of the HAZ and the matrix

Fig.3 The Micro-structure of 16Mn Steel Welding Joints

\section{Grain Size Measurement of 16Mn Steel Welding Joints}

Fig.4(a)-(c) is grain size of the matrix, the HAZ and the weld seam. From the picture, in the HAZ, every region is affected by circulation heat, the grain grows up increasingly with the circulation heat. In contrast, grains of HAZ are the biggest, the weld seam is the second, the matrix is the minimum. Through measure, the average grain size of the matrix is $21.5 \mu \mathrm{m}$, weld seam is $26.9 \mu \mathrm{m}$, and HAZ $27.7 \mu \mathrm{m}$.

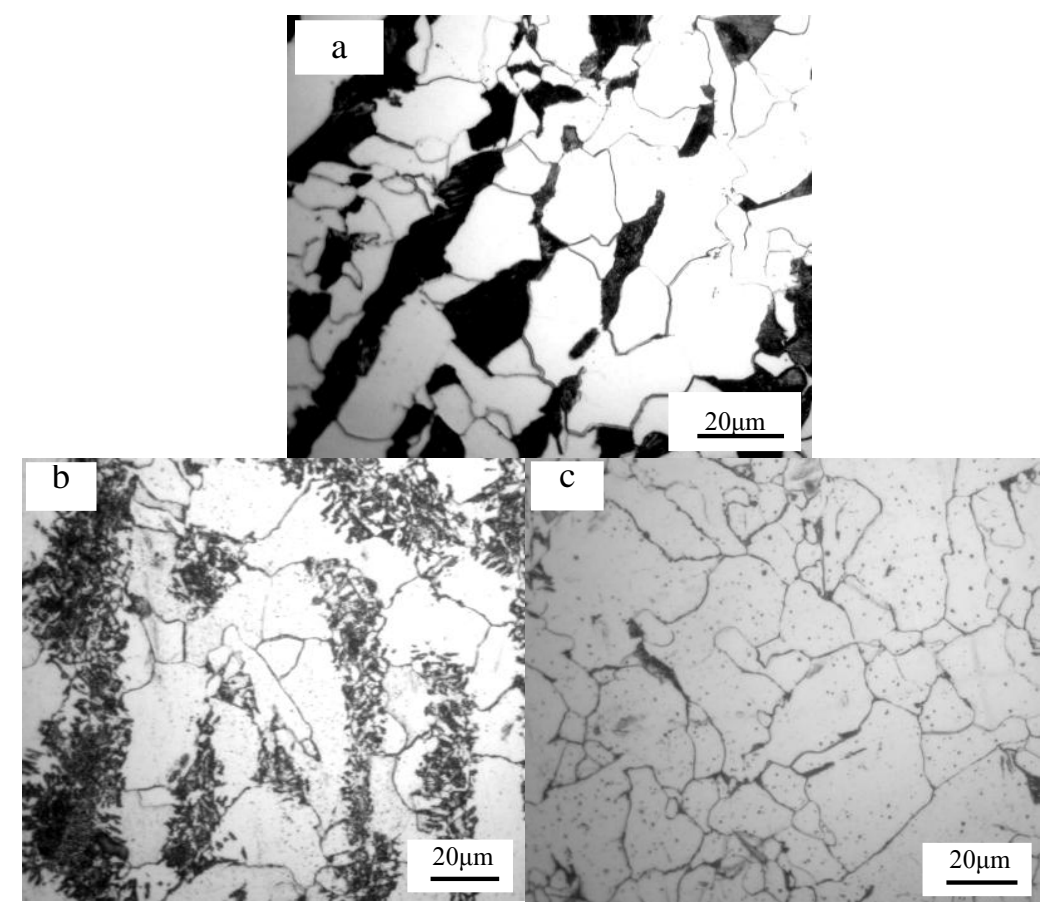

Fig.4 The Grain Size Picture of 16Mn Steel Welding Joints (a) Matrix(b HAZ(c)Weld zoneyin 


\section{Micro-hardness Measurement of 16Mn Steel Welding Joints}

In the one side matrix for the origin, the horizontal coordinate is the distance of the matrix to the weld centre line and the vertical coordinate is the micro-hardness. The hardness curve is depicted as Fig.5. According to the hardness curve, The micro-hardness achieves peak in the boundaries of weld seam and the HAZ. The micro-hardness of the weld seam is low. In the boundaries of the weld seam and the HAZ, the cooling speed is fast, ferrite in least quantity and pearlite in greater quantity. Pearlite is a two-phase including ferrite and cementite. The hardness of pearlite is higher than ferrite, so the micro-hardness here reaches the maximum, about $250 \mathrm{HV}$.

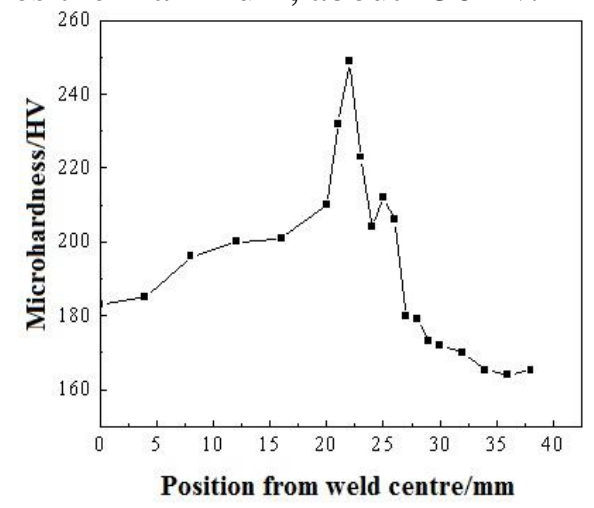

Fig.5 The Micro-hardness of 16Mn Steel Welding Joints

\section{Conclusions}

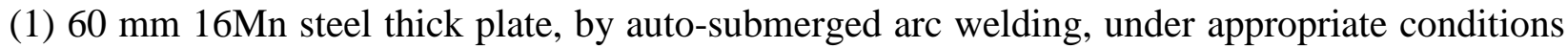
in DC, weld seam is possible to obtain good quality, the micro-structure is uniform too.

(2) The micro-structure of $16 \mathrm{Mn}$ steel welded joint is ferrite + pearlite. It is found that there is ferrite widmanstatten structure in the fusion zone. The contents of pearlite is highest in the boundaries of the weld seam and the HAZ.

(3)In the welding joints of $16 \mathrm{Mn}$ steel, the grain size of HAZ is the biggest, weld seam is second and matrix is the smallest

(4)In the welding joints of $16 \mathrm{Mn}$ steel, the micro-hardness achieves peak in the boundaries of weld seam and the HAZ. The maximum of the micro-hardness is about $250 \mathrm{HV}$.

\section{References}

[1]Z.Zou. Handbook of Welding Materials Technology and Equipment [M]. Beijing: Chemical Industry Press, 2001, 5.

[2]J.Cao, H.Luo, Z.Han. Acoustic emission source mechanism analysis and crack length prediction during fatigue crack propagation in 16Mn steel and welds [J]. Procedia Engineering,27 (2012): 1526-1527.

[3]W.Xu, J.Liu, D.Chen, G.Luan, J.Yao. Improvements of strength and ductility in aluminum alloy joints via rapid cooling during friction stir welding [J]. Materials Science and Engineering A,548 (2012): 92-96.

[4]Y.Zhao, J.Dong, L.Zhao, Y.Ma, J.Zhou. The Research of 1Cr1 and 1Cr18Ni9Ti Stainless Steel Welding Joint Organization and Performance [J], Welding, 2008, (2):56-59. 